\title{
Influence of Motor Activity on the Development of Voluntary Attention in Children Aged 6-7 Years in Rural and Urban Micro-Community
}

\author{
Larisa M. Zakharova ${ }^{1} \&$ Victoria Zakharova ${ }^{1}$ \\ ${ }^{1}$ Ulyanovsk State Pedagogical University, Ulyanovsk, Russia \\ Correspondence: Victoria Zakharova, Ulyanovsk State Pedagogical University, Ulyanovsk, Russia. E-mail: \\ vic2488z@gmail.com
}

Received: November 13, 2017

Accepted: December 28, 2017 Online Published: March 28, 2018

doi:10.5539/ies.v11n4p126

URL: https://doi.org/10.5539/ies.v11n4p126

\begin{abstract}
The article is devoted to the problem of the influence of physical activity on the development of voluntary attention in children aged 5-7, which largely determines the success of schooling. The studies conducted in different countries prove the existence of such a correlation, which, at the same time, is not always unambiguous. We studied the nature of this correlation in the children of rural and urban kindergarten. The results of the pilot study showed that there were no significant differences in the development of the basic indicators of voluntary attention among the rural children attending various sports clubs and those who do not go in for sports, in contrast to the children attending kindergarten in the city. The influence of the family on the children's desire to lead an active lifestyle has been also determined.
\end{abstract}

Keywords: motor activity, attention, child, influence, kindergarten, micro-community

\section{Introduction}

\subsection{Introduction to the Problem}

The preschool period is characterized by the intensive development of the mental and motor spheres, which determines the success of socialization and predetermines its readiness for schooling. The primary school student should perceive, comprehend and memorize the educational material, which may or may not always be interesting; they should act in accordance with the instructions, self-organize, carry out cognitive activities, and make volitional efforts. The intensification of the research devoted to the study of voluntary attention in primary schoolchildren is connected with the children's unreadiness for schooling, as well as the inability to set tasks for themselves and to keep track of those tasks. In this respect, an increased focus is placed on the preschool period, when children learn how to manage their attention.

The development of voluntary attention by the end of the preschool age ensures the success of the organization of learning activities.

Initially the child's attention is associated with their interest in the surrounding objects. Their focus appears only as long as the objects arouse interest. At the senior preschool age (5-7 years), children begin to hold attention due to the appearance of the intellectually significant interest (riddles, puzzle games). The sustainability of attention in intellectual activities increases significantly by the age of seven (Mukhina, 2003).

\subsection{Conceptual Frame of Study}

Nowadays the problem of attention is actively being analyzed by psychologists, neurologists, and educators. Psychologists are examining attention with regard to the activity approach (B. G. Ananev, S. L. Rubinshtein), from the perspective of installation psychology (D. N. Yznadze), control activities (P. Ia. Galperin), and as part of cognitive psychology. The main mechanisms, conditions, peculiarities of attention development are being taken into consideration (R. I. Machinskaiaя, N. M. Safronova, N. A. Pakhomova, G. P. Pozdniakova, etc.). The main condition for the development of the attention arbitrariness is the development of the interest responsible for the speech functions.

The analysis of scientific research allows us to state that the child's physical activity (Pozdniakova G. P.) also contributes to the effective development of voluntary attention at the senior preschool age. According to the numerous studies, there is a direct link between physical activity and cognitive processes (Berchtold, Castello, \& 
Cotman, 2010; Eveland-Sayers, Farley, Fuller, Morgan, \& Caputo, 2009; Sarid \& Zvia Breznitz University of Haifa, Israel, 1997).

When playing sports, blood flow throughout the body is increased, including the brain. The studies conducted by scientists from the University of Texas showed that there is a positive correlation between the increase in cerebral blood flow and the memory improvement. The authors suppose that physical activities, increasing cerebral blood flow, contribute to the memory improvement (Chapman, Aslan, Spence, DeFina, Keebler, Didehbani, \& Hanzhang Lu 2013).

The researchers have come to a conclusion that when playing sports the level of protein required for the growth and development of neurons (BDNF-brain-derived neurotrophic factor) increases (Sleiman et al., 2016).

This protein is most active in those areas responsible for memory and learning (the hippocampus and the cortex of the brain).

Much attention is paid to the problem of the mutual influence of physical activities on the development of cognitive processes. The authors of the experiments conducted search for the most effective ways to organize children's activities which would ensure the development of concentration of children's attention, and increase overall mental performance.

Attention to the child's physical activity has recently become more obvious and necessary. Both parents and teachers note that modern children have become less mobile, they play less, preferring passive pursuits like watching TV and playing computer games, which of course affects their health.

According to the Scientific Centre of children`s health of RAMS (Russian Academy of Medical Sciences), there are only $17.3 \%$ of absolutely healthy preschool children and $70 \%$ of children who have functional and morphofunctional abnormalities.

Age-appropriate physical activity affects people`s physical development, allows them to maintain and improve their health, reduce the incidence. Physical development is considered as a set of morphological and functional features and their interdependence on the environment.

According to researches, physical development is $70 \%$ genetically determined and $30 \%$ depends on exogenous factors such as social and economic living conditions, adult influence, ecology etc. (A. Salemi, N. A. Agadzhanian).

Modern parents associate the success of schooling with the level of readiness of the child for school. Readiness for school is determined, to a greater extent, by the level of acquired knowledge, by the formation of training skills.

In this case, there takes place the static load increases. Usually it happens due to a reduction in the motor activity of children or due to a certain lack of movement. The reduction of the physical activity of a preschool child is also due to the intensification of mental activity, which is not always adequate to its age-related capabilities (Filippova, 2013). There is a paradoxical situation, which is often not realized by many parents. The success of schooling is associated with the child's mental readiness, when the child's growing mental activity before the admission to school "displaces" the physical one. At the same time, it is the optimal physical activity and the motor regime ensures the safety of health, create the basis for successful learning and mental development.

Motor activity, outdoor games, sports exercises not only strengthen children physically, but also improve the overall body performance, including mental activity. Children's natural need for movement, games, spontaneous activity is a way to "optimize one's own brain development" (Burdette \& Whitaker, 2005).

Physical exercises, mobile games at the preschool age develop the ability to act according to instructions, to concentrate, to exert strong-willed efforts. With age, children's physical activity increases and the conditions for its realization become more complicated: children learn to determine the goal of physical activity, choose the type of action to achieve it, monitor and correct their activities. Golovkina (2002) proved the beneficial effect on the overall development of children, the integration of physical and mental activity, when the physical activity at the senior preschool age influences the development of thinking, memory, and attention.

The studies conducted by Kara K. Palmer, Matthew W. Miller, and Leah E. Robinson (with the School of Kinesiology, Auburn University, Auburn, AL) confirm this correlation. The researchers have proven that a thirty-minute one-off physical activity allows children to be more focused on the performance of subsequent tasks related to mental activity. It has been proved that after physical exercises ( 30 minutes at a sitting) the possibility to hold attention among senior preschool age children increases; they perform tasks that require mental effort more effectively. It has also been noted that children playing active games are more concentrated than those who play quiet games (Palmer, Miller, \& Robinson, 2013). 
At the same time, the researchers emphasize that not all physical activity leads to such results, but only those that require concentration of attention (throwing a ball, jumping from goal to goal), as contrasted with simple running, jumping or crawling.

A study revealing the correlation between the mental and physical development of preschool children (Antonov, 1997) showed that the level of children's physical activity in kindergartens is quite low. The method of using elements of mobile games in the educational process proposed by the author gave positive results in increasing the level of children's physical readiness, cognitive activity, and motor sensitivity. Physical activity for brain health can explain the increase in academic performance (Tomporowski, 2003).

However, the correlation between motor activity and the development of voluntary attention is not confirmed in all studies conducted. An analysis of the scientific studies, summarized by Keeley and Fox (2009) showed that the direct correlation between physical activity and cognitive functions is not sufficiently proven. In the meantime, there is no evidence that physical stress deteriorates cognitive abilities. There is a weak dependence, which, according to the authors, is not sufficiently proven.

The study of scientific results obtained by the researchers allows us to state that the development of children's attention of the senior preschool age is determined to some extent and depends on the type of physical activity, duration of studies, and integration with various types of children's activities. In kindergartens, the upbringing and education of preschool children is carried out in accordance with educational standards in which physical development is determined among important activities. The physical development of a child at the preschool age is associated with the acquisition of experience in motor activity, the development and flexibility; the formation of purposefulness and self-regulation, the formation of values of a healthy lifestyle, the formation of initial ideas about certain sports, and others. The Federal State Standard of Preschool Education regulates the main directions of educational activity in kindergartens and gives parents a reference point for family education in the sphere of physical, mental, social development of a child.

Since educational programs used in kindergartens adhere to a unified position for the purposes and tasks of educational work, educators organize children's physical activity in accordance with the program. The question now arises of whether the specific nature of the child's sociocultural environment influences children's physical activity and, respectively, the development of attention?

\subsection{Purpose of Research}

This study aims to answer the following questions: Do indicators of voluntary attention depend on the physical activity of 6-7 year-old children? Are there any differences in these indicators in children who go and do not go in for sports? Do these differences exist in children who attend rural and urban kindergartens? Does the specificity of the sociocultural environment affect children's physical activity?

\section{Methodology}

\subsection{Participants}

The participants in this study are 39 children (20 in the city and 19 in the countryside) and 50 parents.

\subsection{Instruments}

Children were diagnosed by using the technique "Domik" (N. I. Gutkina), which is used to determine the child's readiness for schooling, and the correction task (Bourdon test). Also we conducted a questionnaire for parents whose children attend a kindergarten (in the city and in the countryside).

\subsection{Procedure}

At the first stages of the study of the influence of physical activity on the development of voluntary attention, a survey was conducted among parents in the city and in the countryside. Considering physical activity as a key aspect of a healthy lifestyle, we developed questionnaires aimed at elucidating the parents' understanding of what a "healthy lifestyle" is (exercise, healthy food, active rest) and adherence to the principles of a healthy lifestyle in the family.

\section{Results}

Distinguishing signs of a healthy lifestyle according to the answers of the majority of respondents were the right (healthy food); absence of bad habits, physical activity (exercise, morning gymnastics).

At the same time, there is no correspondence between understanding the importance and role of a healthy lifestyle and following the principles. Only one third of parents noted that they lead a healthy lifestyle, are engaged in sport clubs, do exercises. Some parents do not care about this problem, the others did not think about it before. 
Among the reasons that are the "obstacles" to maintaining a healthy lifestyle were: lack of time for sports; financial difficulties as there is no possibility to pay for classes in sports clubs. Some parents noted in the questionnaires that there is no need to go in for sports, to lead an active lifestyle, because they are already very busy both at work and at home, they all are healthy in the family. The number of parents living in rural areas and engaged in sports is half as big as the number of parents living in the city. The results of the survey allowed determining the influence of parents who lead a healthy and active lifestyle on the children's desire to do sports.

Within the framework of the questionnaire survey, it was proved that city children $(68.75 \%)$, compared to rural children (21.4\%), are more engaged in sports. Respondents named their favorite children's activities at home. 5-7 year-old children who are engaged in sports prefer active games and walks as free time ( $100 \%$ of children). Among the children who are not involved in sports there are only $80 \%$. In the spare time, city children prefer such sedentary activities as watching TV and playing computer games, which is 4 times as much as among rural children.

Small distances in rural areas allow not using personal and public transport as a means of transportation, and give the opportunity to get to work and kindergarten on foot. This fact affects the degree of daily physical activity of both children and parents. The results of interviews with parents allowed determining the nature of the influence of the social and cultural specificity of residence on the level of physical activity of parents and children.

The second direction of our study was related to the definition of the development level of voluntary attention in 6-year-old children. The important features of voluntary attention are focus and concentration

The technique "Domik" (N. I. Gutkina) was used to determine children's ability to copy the sample, focusing on it, and to state the characteristics of the development of voluntary attention, spatial perception, sensorimotor coordination and fine motor skills. The children were asked to draw a house from a picture, in which individual details are made up of the elements of capital letters.

The results of the diagnosis showed the average level of development of the main indicators in children engaged in physical activities. In the rural kindergarten is $33.3 \%$, in the city is $57.2 \%$. Low development of indicators in the rural kindergarten is $66.6 \%$ and in the cityis $42,8 \%$, respectively (Table 1 ).

Table 1. The results of the diagnosis method "Domik"

\begin{tabular}{ccccc}
\hline \multirow{2}{*}{ Development of indicators } & \multicolumn{2}{c}{ Children engaged in sports } & \multicolumn{2}{c}{ Children not engaged in sports } \\
\cline { 2 - 5 } & City kindergarten (\%) & Rural kindergarten (\%) & City kindergarten (\%) & Rural kindergarten (\%) \\
\hline Average & 57.2 & 33.3 & - & 36.3 \\
Low & 42.8 & 66.6 & 100 & 63.7 \\
\hline
\end{tabular}

The comparative analysis of the attention development within two groups of children from rural kindergarten using the Mann-Whitney $U$ test criterion $(p<0.05)$ showed that there are no significant differences in the development of basic indicators in the children attending a rural kindergarten. In our opinion, that can be explained by the sociocultural, natural specificity of the educational system of the countryside: a considerable amount of time spent by children in the open air and their activity favorably affect children's physical health. Involvement in looking after domestic animals and doing the housework contribute to the development of physical qualities, concentration, responsibility, discipline, and the ability to focus on the task.

Reliable differences in the criterion of the Mann-Whitney $U$ test $(p<0.05)$ were obtained only in two groups of children who attend a kindergarten in the city.

Children who do not go in for sports and attend a kindergarten in the city are dominated by a low level of development of the key indicators.

To determine the sustainability and concentration of attention, a correction task (Bourdon test, children's form) was used, where children had to draw either a window (in a house) or a twig (with a leaf). The results were estimated by the number of missing or corresponding painted details and the completion rate. Concentration of attention was estimated by the formula $\mathrm{K}=\mathrm{C}^{2} / \mathrm{P}$, where $\mathrm{C}$ is the number of rows of the table viewed by the subject, and $\mathrm{P}$ is the number of errors (omissions or erroneous deletions of unnecessary signs). The sustainability of attention was assessed by changing the speed of viewing throughout the entire task. The results are calculated every 60 seconds according to the formula: $\mathrm{A}=\mathrm{S} / \mathrm{t}$, where $\mathrm{A}$ is the completion rate, $\mathrm{S}$ is the number of pictures in the viewed part of correction task, $\mathrm{t}$ is the completion time.

The results of determining the attention stability of children in rural and urban kindergartens are presented in Table 
2.

Table 2. The results of the Bourdon test

\begin{tabular}{ccccc}
\hline \multirow{2}{*}{$\begin{array}{c}\text { Sustainability and concentration of } \\
\text { attention }\end{array}$} & \multicolumn{2}{c}{ Children engaged in sports } & \multicolumn{2}{c}{ Children not engaged in sports } \\
\cline { 2 - 5 } & $\begin{array}{c}\text { City kindergarten } \\
(\%)\end{array}$ & $\begin{array}{c}\text { Rural kindergarten } \\
(\%)\end{array}$ & $\begin{array}{c}\text { City kindergarten } \\
(\%)\end{array}$ & $\begin{array}{c}\text { Rural kindergarten } \\
(\%)\end{array}$ \\
\hline High & 57.2 & 66.6 & 28.5 & 63.7 \\
Average & 14.3 & 33.3 & 14.3 & 27 \\
Low & 28.5 & & 57.2 & 9.3 \\
\hline
\end{tabular}

The difference in the results of the diagnostics performed on the sustainability and concentration of attention is observed in children attending a city kindergarten. High level of concentration and sustainability of attention was shown by children engaged in sports is $57.2 \%$. The number of children who do not go in for sports with a high level of concentration and sustainability of attention equals to $28.5 \%$. As before, there were no special differences in the level of concentration and sustainability of attention in children who are both engaged in sports and who are not in a rural kindergarten.

\section{Conclusion and Suggestions}

In conclusion, we can sum up the obtained results. There is a definite relationship between physical activity and the development of cognitive activity. The development of the physical and mental activities of children is influenced by the specifics of the sociocultural environment, both at the family level and at the level of micro-society (a city and a village). The conducted research has allowed tracing the interrelation between a way of life of a family and desire of children to adhere to an active way of life.

The data of the research conducted allow assuming that the active lifestyle physical activities connected with engagement in sports and fitness classes and with doing the housework affect the mental activity of children of the senior preschool age. Since this requires remembering the task set by the coach or parents, it is important to be able to keep it for a certain time and be focused on completing the task.

The study allowed tracing the correlation between the family's lifestyle and children's desire to lead an active lifestyle. The study of children's attention in rural kindergarten did not reveal significant differences in the concentration and sustainability of children's attention, who are both engaged in sports and who are not, at the same time, the efforts of both parents and kindergarten teachers should be aimed at inculcating a healthy lifestyle, integration of physical and mental activity. In city kindergartens, it is necessary to increase the proportion of children's physical activity, providing an opportunity for classes in sports clubs as supplementary education, including those organized by a kindergarten.

At the same time, attention is one of the components of cognitive activity. In this regard, it is possible to single out one more area of educational work in kindergartens. It is aimed at developing attention and it is associated with the activation of cognitive activity of children, the development of their interest in knowing the environment. A specific socio-cultural, natural environment is the reality in which the child develops; this is the means and the condition for his cognitive and physical development. The process of cognition of sociocultural reality takes place as a result of the integration of mental and physical activity. Walking and cycling in the summer, skiing in the winter provide physical activity, concentration of attention, concentration on observance of the rules of movement, techniques of performance, on the one hand. They provide mental activity, maintaining interest in "discovering" something about the appearance of geographical objects (lakes, groves, mounds, etc.); the history of the emergence of architectural forms, the culture and traditions of a specific location, on the other hand.

The activation of the child's mental and physical activities is carried out within the process of his independent activity in the process of daily interaction and as a result of the educational influence of adults. An effective means of developing voluntary attention, cognitive processes is the integration of mental and physical activities in the kindergarten.

\section{References}

Antonov, A. A. (1997). Method of Application of Mobile Games Elements for Developing Cognitive Activity of Senior Preschool Children (Ph.D. thesis, St. Petersburg).

Berchtold, N. C, Castello, N., Cotman, C. W. (2010). Exercise and time-dependent benefits to learning and memory. Neuroscience, 167(3), 588-597. https://doi.org/10.1016/j.neuroscience.2010.02.050 
Burdette, H. L., \& Whitaker, R. C. (2005). Resurrecting Free Play in Young Children: Looking Beyond Fitness and Fatness to Attention, Affiliation and Affect. Arch Pediatr Adolesc Med, 159(1), 46-50. https://doi.org/10.1001/archpedi.159.1.46

Chapman, S. B., Aslan, S., Spence, J. S., Defina, L. F., Keebler, M. W., Didehbani, N., \& Lu, H. (2013). Shorter term aerobic exercise improves brain, cognition, and cardiovascular fitness in aging. Frontiers in Aging Neuroscience. https://doi.org/10.3389/fnagi.2013.00075

Eveland-Sayers, B. M., Farley, R. S., Fuller, D. K., Morgan, D. W., \& Caputo, J. L. (2009). Physical Fitness and Academic Achievement in Elementary School Children. Journal of Physical Activity and Health, 6, 99-104. https://doi.org/10.1123/jpah.6.1.99

Filippova, T. A. (2013). Physical Development and Health Condition of Preschool and Primary School Children. New researches, 145-158.

Golovkina, A. A. (2002). Integration of Motor and Cognitive Activity of Senior Preschool Children (Ph.D. thesis, Shuya).

Keeley, T. J. H., \& Fox, K. R. (2009). The impact of physical activity and fitness on academic achievement and cognitive performance in children. International Review of Sport and Exercise Psychology, 2(2), 198-214. https://doi.org/10.1080/17509840903233822

Mukhina, V. S. (2003). Age Psychology: Phenomenology of Development, Childhood, Adolescence: Textbook for University Students (7th ed., pp. 203-205). Moscow: Publishing House "Akademiya".

Pakhomova, N. A. (2003). Development of Voluntary Attention among First-year school Children according to the Conditions of Education, Nizhny Novgorod.

Palmer, K. K., Miller, M. W., \& Robinson L. E. (2013). Acute Exercise Enhances Preschoolers' Ability to Sustain Attention. Journal of Sport \& Exercise Psychology, 35, 433-437. https://doi.org/10.1123/jsep.35.4.433

Sarid, M., \& Breznitz, Z. (1997). Developmental Aspects of Sustained Attention among 2- to 6-year-old Children. International journal of behavioral development, 21(2), 303-312. https://doi.org/10.1080/016502597384884

Sleiman, S. F., Henry, J., Al-Haddad, R., Hayek, E. L., Abou Haidar, E., Stringer, T., ... Chao, M. V. (2016). Exercise promotes the expression of brain derived neurotrophic factor (BDNF) through the action of the ketone body $\beta$-hydroxybutyrate.

Stasevich, K. (2017). Physical activity and brain. Science and Life, 9, 38-41.

Tomporowski, P. D. (2003). Effects of acute bouts of exercise on cognition. Acta Psychol, 112(3), 297-324. https://doi.org/10.1016/S0001-6918(02)00134-8

Vinogradova, E. L. (2004). Conditions for the Formation of Cognitive Motivation of Senior Preschool Children (Ph.D. thesis, Moscow).

\section{Copyrights}

Copyright for this article is retained by the author(s), with first publication rights granted to the journal.

This is an open-access article distributed under the terms and conditions of the Creative Commons Attribution license (http://creativecommons.org/licenses/by/4.0/). 